\title{
Chemical characterization of oligosaccharides in the milk of six species of New and Old world monkeys
}

\author{
Kohta Goto $\cdot$ Kenji Fukuda $\cdot$ Akitsugu Senda $\cdot$ Tadao Saito $\cdot$ Kazumasa Kimura $\cdot$ \\ Kenneth E. Glander • Katie Hinde • Wolfgang Dittus • Lauren A. Milligan • \\ Michael L. Power • Olav T. Oftedal • Tadasu Urashima
}

Received: 9 August 2010 /Revised: 11 November 2010 /Accepted: 11 November 2010/Published online: 3 December 2010

(C) The Author(s) 2010. This article is published with open access at Springerlink.com

\begin{abstract}
Human and great ape milks contain a diverse array of milk oligosaccharides, but little is known about the milk oligosaccharides of other primates, and how they differ among taxa. Neutral and acidic oligosaccharides were isolated from the milk of three species of Old World or catarrhine monkeys (Cercopithecidae: rhesus macaque (Macaca mulatta), toque macaque (Macaca sinica) and Hamadryas baboon (Papio hamadryas)) and three of New World or platyrrhine monkeys (Cebidae: tufted capuchin (Cebus apella) and Bolivian squirrel monkey (Saimiri boliviensis); Atelidae: mantled howler (Alouatta palliata)). The milks of these species contained 6-8\% total sugar, most of which was lactose: the estimated ratio of oligosaccharides to lactose in
\end{abstract}

Electronic supplementary material The online version of this article (doi:10.1007/s10719-010-9315-0) contains supplementary material, which is available to authorized users.

K. Goto $\cdot$ K. Fukuda $\cdot$ A. Senda $\cdot$ T. Urashima $(\bowtie)$

Graduate School of Food Hygiene,

Obihiro University of Agriculture \& Veterinary Medicine,

Obihiro, Hokkaido 080-8555, Japan

e-mail: urashima@obihiro.ac.jp

T. Saito

Graduate School of Agriculture, Tohoku University,

Sendai, Japan

\section{K. Kimura}

Yakult Central Institution,

Kunitachi, Japan

K. E. Glander

Department of Evolutionary Anthropology, Duke University,

Durham, NC, USA

\section{K. Hinde}

Brain, Mind, \& Behavior Unit, California National Primate Research Center, University of California Davis,

Davis, CA, USA
Old World monkeys (1:4 to $1: 6)$ was greater than in New World monkeys (1:12 to $1: 23)$. The chemical structures of the oligosaccharides were determined mainly by ${ }^{1} \mathrm{H}-\mathrm{NMR}$ spectroscopy. Oligosaccharides containing the type II unit $(\operatorname{Gal}(\beta 1-4)$ GlcNAc) were found in the milk of the rhesus macaque, toque macaque, Hamadryas baboon and tufted capuchin, but oligosaccharides containing the type I unit $(\mathrm{Gal}(\beta 1-3) \mathrm{GlcNAc})$, which have been found in human and many great ape milks, were absent from the milk of all species studied. Oligosaccharides containing Lewis $\mathrm{x}$ (Gal $(\beta 1-4)[\mathrm{Fuc}(\alpha 1-3)] \mathrm{GlcNAc})$ and 3-fucosyl lactose (3-FL, Gal $(\beta 1-4)[\mathrm{Fuc}(\alpha 1-3)] \mathrm{Glc})$ were found in the milk of the three cercopithecid monkey species, while 2-fucosyl lactose

W. Dittus

Smithsonian Primate Biology Program,

Institute of Fundamental Studies,

Kandy, Sri Lanka

L. A. Milligan

Department of Anthropology, University of California Santa Cruz, Santa Cruz, CA, USA

W. Dittus $\cdot$ M. L. Power

Nutrition Laboratory, Smithsonian Conservation Biology Institute,

National Zoological Park,

Washington DC, DC, USA

O. T. Oftedal

Smithsonian Environmental Research Center,

Edgewater, MD, USA 
(5'-FL, Fuc $(\alpha 1-2) \operatorname{Gal}(\beta 1-4)$ Glc) was absent from all species studied. All of these milks contained acidic oligosaccharides that had $\mathrm{N}$-acetylneuraminic acid as part of their structures, but did not contain oligosaccharides that had $N$ glycolylneuraminic acid, in contrast to the milk or colostrum of great apes which contain both types of acidic oligosaccharides. Two GalNAc-containing oligosaccharides, lactose 3'-O-sulfate and lacto-N-novopentaose I $(\mathrm{Gal}(\beta 1-3)[\mathrm{Gal}(\beta 1-$ 4) GlcNAc( $(\beta 1-6)] \operatorname{Gal}(\beta 1-4) \mathrm{Glc})$ were found only in the milk of rhesus macaque, hamadryas baboon and tufted capuchin, respectively. Further research is needed to determine the extent to which the milk oligosaccharide patterns observed among these taxa represent wider phylogenetic trends among primates and how much variation occurs among individuals or species.

Keywords Old world monkey · New world monkey· Milk oligosaccharide $\cdot$ Rhesus macaque $\cdot$ Toque macaque .

Baboon - Capuchin - Mantled howler - Squirrel monkey ·

$\mathrm{N}$-glycolylneuraminic acid

\section{Introduction}

Human colostrum and mature milk contain $22 \sim 24 \mathrm{~g} / \mathrm{L}$ and 12 $\sim 13 \mathrm{~g} / \mathrm{L}$, respectively, of a large variety of oligosaccharides [1, 2], which collectively represent the third largest solid component of milk after lactose and lipids. To date the chemical structures of at least 115 human milk oligosaccharides have been characterized [3-5]. We have recently shown that the predominant oligosaccharides in human colostrum obtained during the first 3 days of lactation are 2'-FL, LNFPI $(\operatorname{Fuc}(\alpha 1-2) \operatorname{Gal}(\beta 1-3) \operatorname{GlcNAc}(\beta 1-3) \mathrm{Gal}(\beta 1-4) \mathrm{Glc})$, LNDFHI $(\operatorname{Fuc}(\alpha 1-2) \operatorname{Gal}(\beta 1-3)[\operatorname{Fuc}(\alpha 1-4)] \operatorname{GlcNAc}(\beta 1-3) \operatorname{Gal}(\beta 1-4)$
Glc) and LNT $(\operatorname{Gal}(\beta 1-3) \operatorname{GlcNAc}(\beta 1-3) \mathrm{Gal}(\beta 1-4) \mathrm{Glc})$ [6]. These four oligosaccharides are also predominant in transitional and mature human milk [7-9]. It is noteworthy that LNFPI, LNDFHI and LNT all contain the type I unit $(\mathrm{Gal}(\beta 1-$ 3)GlcNAc, lacto-N-biose I) within their structures, in contrast to the oligosaccharides of the milk or colostrum of a wide variety of non human mammals, all of which have been shown to contain predominantly or, in most cases exclusively, the type II unit (Gal( $\beta 1-4)$ GlcNAc, $N$-acetyllactosamine) [3].

Recently, we studied the milk oligosaccharides of a hylobatid (the siamang) and of the great apes (chimpanzee, bonobo, gorilla and orangutan), which among living primates are the species most closely related to humans [10]. The milk or colostrum of chimpanzee, bonobo and orangutan contained both type I and type II oligosaccharides, but type II predominated over type I, while the milk or colostrum of gorilla and siamang contained only type II oligosaccharides. These observations suggested that the predominance of type I oligosaccharides in milk/colostrum may be a feature that is specific to humans. It is generally believed that human milk oligosaccharides act as soluble receptor analogs that inhibit the attachment of pathogenic bacteria, viruses, and bacterial toxins to the mucosa of the infant colon, and as prebiotics that stimulate the growth of beneficial bifidus bacterial flora [3]. The biological significance of the predominance of type I oligosaccharides in human milk is unknown, but we believe that it may be advantageous to bifidus flora formation in the infant colon.

In this study, we have characterized the milk oligosaccharides of several species of New World and Old World monkeys in order to examine whether type I and/or type II oligosaccharides occur in their milks and also to obtain further information on the phylogenetic distribution of milk oligosaccharides among primates.

Table 1 Milk oligosaccharides characterized in this study

\begin{tabular}{|c|c|}
\hline Oligosaccharides (abbreviation) & Chemical structure \\
\hline 3-Fucosyllactose (3-FL) & $\operatorname{Gal}(\beta 1-4)[\operatorname{Fuc}(\alpha 1-3)] \mathrm{Glc}$ \\
\hline 3'-Galactosyllactose (3'-GL) & $\operatorname{Gal}(\beta 1-3) \mathrm{Gal}(\beta 1-4) \mathrm{Glc}$ \\
\hline $3^{\prime}-N$-acetylgalactosaminyllactose (3'-GalNAcL) & $\operatorname{GalNAc}(\beta 1-3) \operatorname{Gal}(\beta 1-4) \mathrm{Glc}$ \\
\hline Lacto-N-neotetraose (LNnT) & $\operatorname{Gal}(\beta 1-4) \mathrm{GlcNAc}(\beta 1-3) \mathrm{Gal}(\beta 1-4) \mathrm{Glc}$ \\
\hline Lacto-N-fucopentaose III (LNFP III) & $\operatorname{Gal}(\beta 1-4)[\operatorname{Fuc}(\alpha 1-3)] \operatorname{GlcNAc}(\beta 1-3) \operatorname{Gal}(\beta 1-4) \mathrm{Glc}$ \\
\hline Lacto-N- novopentaose I (novo-LNP I) & $\operatorname{Gal}(\beta 1-3)[\operatorname{Gal}(\beta 1-4) \operatorname{GlcNAc}(\beta 1-6)] \mathrm{Gal}(\beta 1-4) \mathrm{Glc}$ \\
\hline Lacto-N-neohexaose (LNnH) & $\operatorname{Gal}(\beta 1-4) \operatorname{GlcNAc}(\beta 1-3)[\operatorname{Gal}(\beta 1-4) \operatorname{GlcNAc}(\beta 1-6)] \operatorname{Gal}(\beta 1-4) \mathrm{Glc}$ \\
\hline Difucosyl-lacto-N-neohexaose (DFLNnH) & $\operatorname{Gal}(\beta 1-4)[\operatorname{Fuc}(\alpha 1-3)] \operatorname{GlcNAc}(\beta 1-3)\{\operatorname{Gal}(\beta 1-4)[\operatorname{Fuc}(\alpha 1-3)] \operatorname{GlcNAc}(\beta 1-6)] \operatorname{Gal}(\beta 1-4) \operatorname{Glc}$ \\
\hline $3^{\prime}-N$-acetylneuraminyllactose (3'-NAc-SL) & $\operatorname{Neu} 5 \operatorname{Ac}(\alpha 2-3) \operatorname{Gal}(\beta 1-4)$ Glc \\
\hline $6^{\prime}-N$-acetylneuraminyllactose $\left(6^{\prime}-\mathrm{NAc}-\mathrm{SL}\right)$ & Neu5Ac $(\alpha 2-6) \mathrm{Gal}(\beta 1-4) \mathrm{Glc}$ \\
\hline $\mathrm{GM}_{2}$ tetrasaccharide $\left(\mathrm{GM}_{2}\right.$ tetra $)$ & GalNAc $(\beta 1-4)[\operatorname{Neu} 5 \operatorname{Ac}(\alpha 2-3)] \operatorname{Gal}(\beta 1-4) \mathrm{Glc}$ \\
\hline Sialyl-lacto-N-tetraose c (LSTc) & $\operatorname{Neu} 5 \operatorname{Ac}(\alpha 2-6) \operatorname{Gal}(\beta 1-4) \operatorname{GlcNAc}(\beta 1-3) \operatorname{Gal}(\beta 1-4) \mathrm{Glc}$ \\
\hline Monosialyl-lacto-N-neohexaose (MSLNnH) & $\operatorname{Neu} 5 \operatorname{Ac}(\alpha 2-6) \operatorname{Gal}(\beta 1-4) \operatorname{GlcNAc}(\beta 1-3)[\operatorname{Gal}(\beta 1-4) \operatorname{GlcNAc}(\beta 1-6)] \mathrm{Gal}(\beta 1-4) \mathrm{Glc}$ \\
\hline $3^{\prime}$-o-lactose sulfate $\left(\mathrm{L}-3^{\prime}-\mathrm{s}\right)$ & $\operatorname{Gal}(\beta 1-4)$ Glc-3'-o-sulfate \\
\hline
\end{tabular}




\section{Materials and methods}

Sample and reference materials

Milk samples were obtained via a number of collaborative research projects and shipped to the Nutrition Laboratory, Smithsonian National Zoological Park. They were kept frozen at $-20^{\circ} \mathrm{C}$ until thawed for analysis. The following samples were obtained:

(1) Rhesus macaque (Cercopithecidae: Macaca mulatta) milk $(9.0 \mathrm{~mL}$ total) was collected at $91,93,95,106$, $113,115,119,120$ and 123 days postpartum from nine lactating females at the California National Primate Research Center, Davis, CA. All females were adult (mean age \pm SD was $8.9 \pm 0.9$ years), had previously reproduced (mean parity \pm SD was $5.3 \pm 1.3$ ), and 4/9 were rearing sons. Mothers were separated from their infants for 3.5-4 h to prevent nursing. Following milk accumulation, mothers were sedated with ketamine hydrochloride $(10 \mathrm{mg} / \mathrm{kg})$ and administered exogenous oxytocin to induce milk let down [2 IU/ $/ \mathrm{kg}(0.1 \mathrm{ml} / \mathrm{kg})$ IM]. Milk was obtained by hand-milking.

(2) Toque macaque (Cercopithecidae: Macaca sinica) milk $(10 \mathrm{~mL})$ was collected at 2.4 months postpartum from two lactating females (2339 and 2340) captured in dry evergreen forest at Polonnaruwa, Sri Lanka (see [11] for a description of the study site and study population). The females were baited into mesh holding traps with cooked rice, chemically immobilized with $4 \mathrm{mg}$ ketamine hydrochloride [12] and injected IM with $0.20 \mathrm{cc}$ (4 IU) oxytocin to induce milk let down. Milk was obtained by hand-milking.

(3) Hamadryas baboon (Cercopithecidae: Papio hamadryas) milk $(5 \mathrm{~mL})$ was collected at 157,190 and 242 days postpartum from three lactating females at the Southwest Foundation for Biological Research, San Antonio, TX. The females in a large group living in an outdoor enclosure were captured for routine veterinary examinations, immobilized with ketamine hydrochloride, injected IM with oxytocin, and milk was obtained by hand-milking. The females were 16.8, 17.5 and 6.1 years of age, weighed 17,23 and $16 \mathrm{~kg}$, and had parities of 8,12 and 1, respectively.

(4) Tufted capuchin (Cebidae: Cebus apella) milk $(7.0 \mathrm{~mL})$ was collected at 43,313 and 348 days postpartum from lactating females from a breeding colony maintained at Alpha Genesis, Inc. (Yemassee, SC) [13]. Mothers were given ketamine hydrochloride at $0.15 \mathrm{ml} / \mathrm{kg}$ IM. Once mothers were sedated (approximately $5 \mathrm{~min}$ ), they were given oxytocin $(0.1 \mathrm{ml} / \mathrm{kg} \mathrm{IM})$. Fifteen to $30 \mathrm{~min}$ after oxytocin injection, milk was manually expressed.
(5) Bolivian Squirrel monkey (Cebidae: Saimiri boliviensis) milk (5.0 mL) was collected 152, 162 and 174 days postpartum from lactating females that were part of a breeding colony maintained at the University of South Alabama Center for Neotropical Primate Research and Resources [14]. The upper torso of each female was wrapped using a self-clinging bandage over gauze pads to prevent nursing or milk loss. Bandages were removed 4-4.5 hr after animal capture. Milk was collected into $15-\mathrm{ml}$ conical tubes by manual expression from the nipple and gentle massage of the underlying mammary gland. Milk was fully expressed by hand from the mammary glands. Oxytocin was not administered.

(6) Mantled howler (Atelidae: Alouatta palliata) milk $(5.3 \mathrm{~mL})$ was collected 1 week, 1 month and 3 months postpartum from lactating females $(76,109$, and 238) at Hacienda La Pacifica, Guanacaste Province, Costa Rica in August 1987 (see [15] for description of the study site and study population). Animals were darted in trees in their home range using the Pneu-Dart ${ }^{\mathrm{TM}}$ system (Pneu-Dart, Inc., HC 31, Williamsport, PA 17701) at a dose rate of $25 \mathrm{mg} / \mathrm{kg}$ of Telazol ${ }^{\circledR}$, and captured in a large net when they fell from the trees into a large net. They were kept sedated with additional doses of $5 \mathrm{mg} / \mathrm{kg}$ of Telazol ${ }^{\circledR}$ administered IM. Milk was collected by hand-milking after IM administration of oxytocin.

Oligosaccharides reference materials (see Table 1 for full names and formulas), LNFP III, LNnT, LNnH, LST c and 2'-FL were purchased from Seikagaku Co. (Tokyo, Japan). $3^{\prime}$-NAc-SL and 6'-NAc-SL were from Sigma Co. (St. Louis, MO). Novo-LNP I was isolated from brown capuchin colostrum [16], while 3'-GL was purified from caprine colostrum [17]. MSLNnH, GM2 tetra and lactose 3'-O-sulfate were isolated from siamang milk [10], bottlenose dolphin milk [18] and dog milk [19], respectively.

Measurement of hexose content of whole milk and colostrum

Milk samples were thawed prior to pooling and assayed for total sugar content by the phenol-sulfuric acid method [20, 21], using lactose monohydrate for preparation of a standard, with results expressed on a lactose equivalent basis.

Preparation of the oligosaccharides from milk/colostrum

Milk samples were pooled within each species (rhesus macaque, toque macaque, Hamadryas baboon, tufted capuchin, Bolivian squirrel monkey and mantled howler) 
to give a sufficient amount $(5-10 \mathrm{ml})$ for oligosaccharide analysis, and thus all results are for pooled samples. Subsamples for oligosaccharide analysis were thawed and extracted with four volumes of chloroform/methanol (2:1, $\mathrm{v} / \mathrm{v})$. After agitation, the emulsion was centrifuged at $5000 \times \mathrm{g}, 4^{\circ} \mathrm{C}$ for $30 \mathrm{~min}$, and the lower chloroform layer and the denatured protein were discarded. The methanol was evaporated from the upper layer, and the lyophilized residue was designated as the carbohydrate fraction.

The carbohydrate fraction from each sample was dissolved in $2 \mathrm{~mL}$ of water, and the solution passed through a BioGel P-2 $(<45 \mu \mathrm{m}, 2.0 \times 100 \mathrm{~cm}$, Bio-Rad, Hercules, CA) that had been calibrated with $2 \mathrm{mg}$ of each of galactose (monosaccharide), lactose (disaccharide) and raffinose (trisaccharide). The gel was washed with $0.1 \mathrm{M} \mathrm{NaOH}$ and $0.1 \mathrm{M} \mathrm{HCl}$ before use. Elution was done with distilled water at a flow rate of $15 \mathrm{~mL} / \mathrm{h}$, and $5 \mathrm{~mL}$ fractions were analyzed for hexose with the phenol- $\mathrm{H}_{2} \mathrm{SO}_{4}$ method [20] and for sialic acid with the periodate-resorcinol method [22] (chromatogram in Figs. 1 and 2). The peak fractions were pooled and lyophilized.

The components in R-2, R-3, R-4, R-6 and R-7 from rhesus macaque milk (Fig. 1a), T-4, T-8 and T-9 from toque macaque milk (Fig. 1b), B-3, B-9 and B-10 from Hamadrys baboon milk (Fig. 1c), C-2, C-3, C-4 and C-6 from tufted capuchin milk (Fig. 2a), S-5 from Bolivian squirrel monkey (Fig. 2b) and M-8 from mantled howler milk (Fig. 2c) were characterized by ${ }^{1} \mathrm{H}-\mathrm{NMR}$ spectroscopy. The component R4 was also characterized by ${ }^{13} \mathrm{C}-\mathrm{NMR}$ and heteronuclear single quantum coherence (HSQC) spectrum.

Fractions R-1 (Fig. 1a), T-1 (Fig. 1b), B-1 (Fig. 1c) and M-1 (Fig. 2c) from the milks of rhesus macaque, toque macaque, Hamadrys baboon, and mantled howler, respectively, were dissolved in $2 \mathrm{ml}$ of $50 \mathrm{mM}$ Trishydroxyaminomethane- $-\mathrm{HCl}$ buffer $(\mathrm{pH} 8.7)$ and subjected to anion-exchange chromatography using a DEAESephadex A-50 (GE Healthcare, Uppsala, Sweden) column $(2.0 \times 20 \mathrm{~cm})$ equilibrated with the same buffer solution. The unadsorbed components were eluted with $250 \mathrm{~mL}$ of the same buffer solution and the adsorbed components were then eluted with a linear gradient of $0-0.5 \mathrm{M} \mathrm{NaCl}$ in the Tris buffer solution. Elution was done at a flow rate of $15 \mathrm{~mL} / \mathrm{h}$ and fractions of $5 \mathrm{~mL}$ were collected. Aliquots $(0.5 \mathrm{~mL})$ of each fraction were analyzed for hexose using the phenol $-\mathrm{H}_{2} \mathrm{SO}_{4}$ method. The fractions of R-1-2 (Fig. 3a), T-1-2 (Fig. 3b), B-1-1 (Fig. 3c) and M-1-2 (Fig. 3d) were each pooled, lyophilized, dissolved in $2 \mathrm{~mL}$ of water and passed through a column $(2.0 \times 35 \mathrm{~cm})$ of BioGel P-2 to remove salts, as described above.

Each component in R-1-2 (Fig. 3a), T-1-2 (Fig. 3b), B1-1 (Fig. 3c), C-1 (Fig. 2a), M-1-2 (Fig. 3d) and S-1 (Fig. 2b) was further purified using HPLC on a TSK gel Amido- 80 column $(4.6 \times 250 \mathrm{~mm}$, pore size $80 \AA$, particle
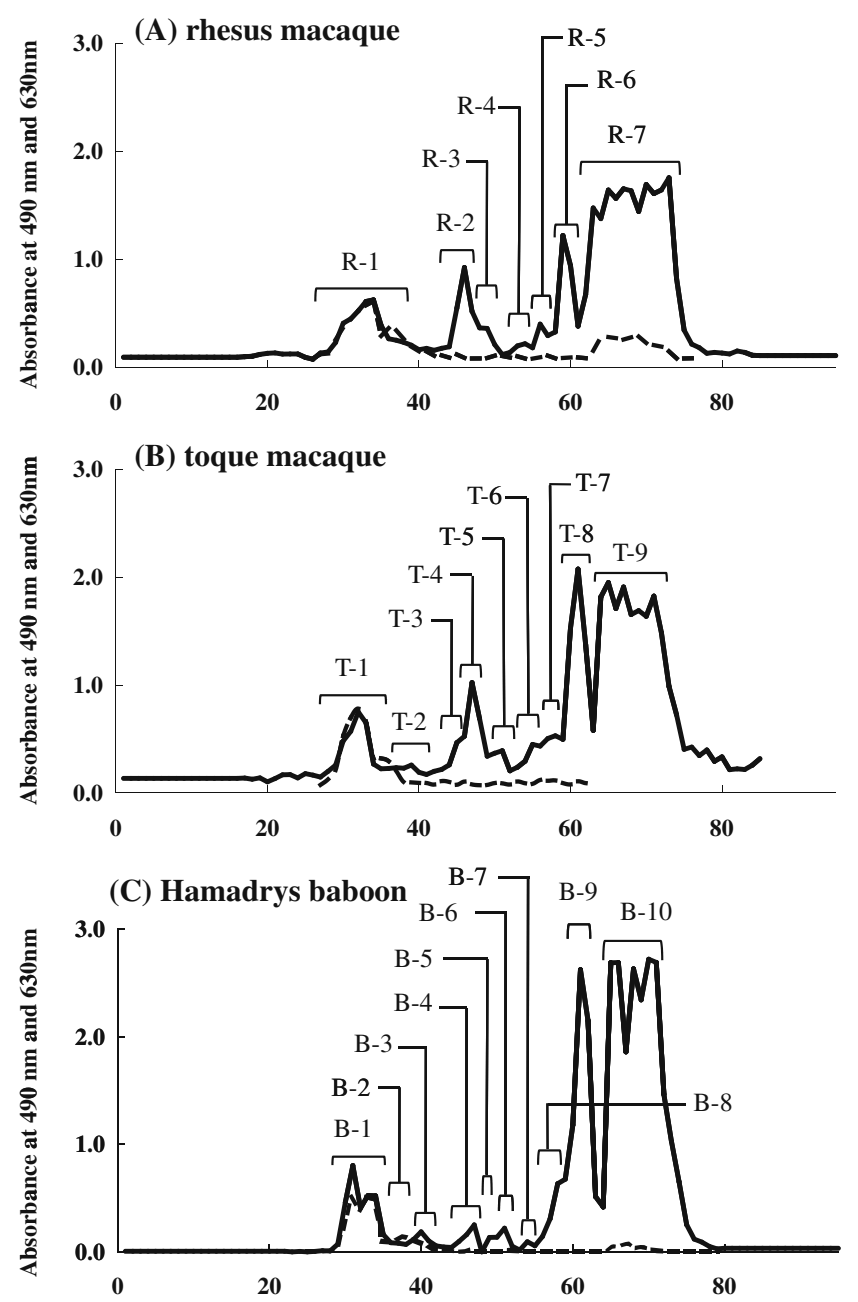

Fig. 1 Gel chromatograms of the carbohydrate fraction from milk of a rhesus macaque, $\mathbf{b}$ toque macaque and $\mathbf{c}$ Hamadryas baboon. Elution from a BioGel P-2 column $(2.6 \times 100 \mathrm{~cm})$ was done with distilled water at a flow rate of $15 \mathrm{~mL} / \mathrm{h}$, and of $5.0 \mathrm{~mL}$ fractions were collected. Each fraction was monitored by the phenol- $\mathrm{H}_{2} \mathrm{SO}_{4}$ method at $490 \mathrm{~nm}$ (as shown in solid line) and the periodate-resorcinol method at $630 \mathrm{~nm}$ (as shown in dot line)

size $5 \mu \mathrm{m}$; Tosho, Tokyo, Japan) using a LC-10ATVP pump (Shimadzu, Tokyo, Japan) (see chromatograms in Figs. 4 and 5). The mobile phase was $50 \%$ and $80 \%(\mathrm{v} / \mathrm{v})$ acetonitrile $\left(\mathrm{CH}_{3} \mathrm{CN}\right)$ in a $15 \mathrm{mM}$ potassium phosphate buffer ( $\mathrm{pH}$ 5.2). Elution was done using a linear gradient of acetonitrile, $80-50 \%$ at $60^{\circ} \mathrm{C}$ at a flow rate of $1 \mathrm{~mL} /$ min. The eluates were monitored by measuring the absorbance at $195 \mathrm{~nm}$. The peak fractions of oligosaccharides were pooled, concentrated by rotary evaporation, and characterized by ${ }^{1} \mathrm{H}-\mathrm{NMR}$.

\section{${ }^{1} \mathrm{H},{ }^{13} \mathrm{C}$ and HSQC NMR spectroscopy}

The NMR spectra were recorded in $\mathrm{D}_{2} \mathrm{O}(100.00$ atom $\mathrm{D} \%$, Aldrich, Milwaukee, USA) at 500 or $600 \mathrm{MHz}$ for ${ }^{1} \mathrm{H}$ - 

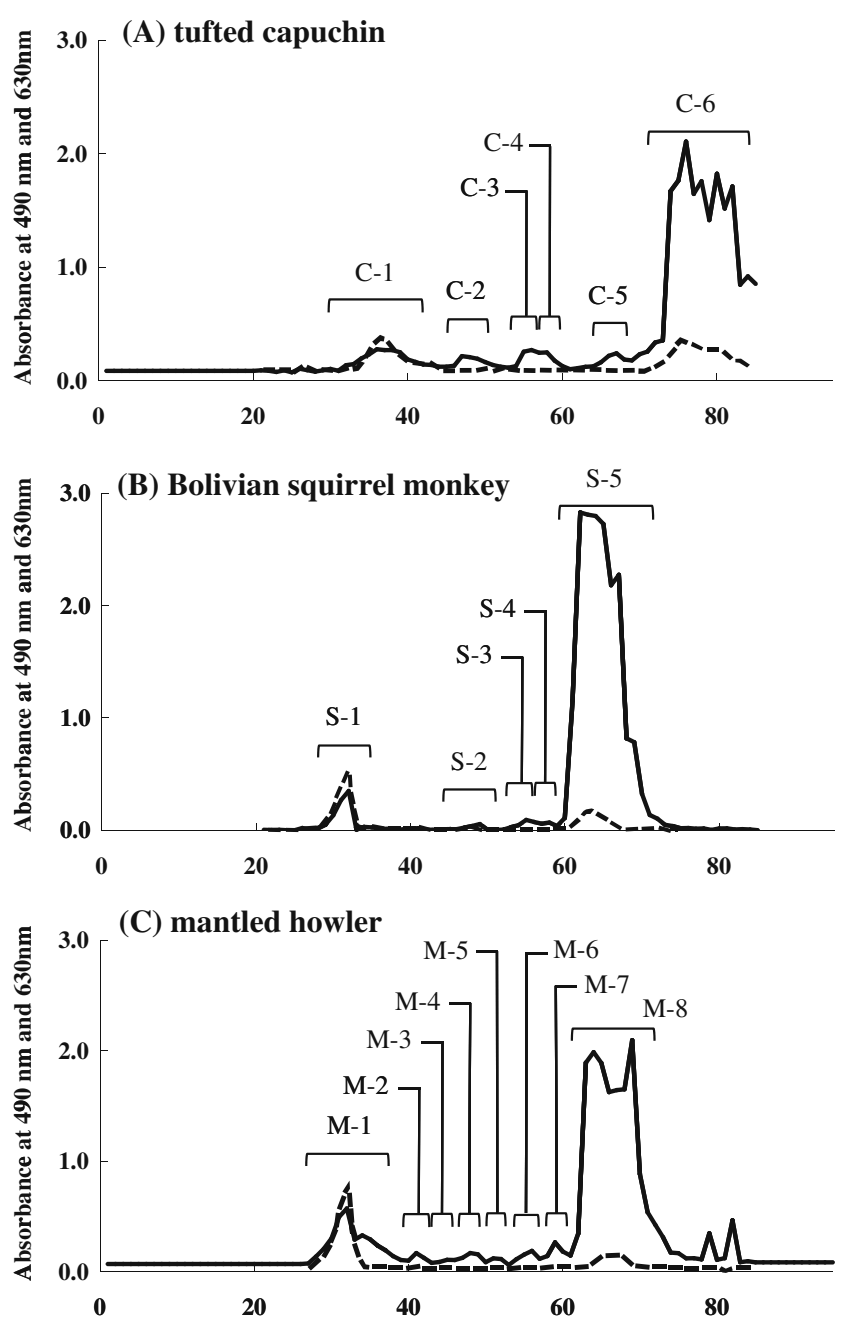

Fig. 2 Gel chromatograms of the carbohydrate fraction from milk of a tufted capuchin, b mantled howler and $\mathbf{c}$ Bolivian squirrel monkey. The gel chromatographies were done as in Fig. 1

NMR with a JEOL-ECP-500 FT-NMR or Varian INOVA 600 spectrometer, and at $125 \mathrm{MHz}$ for ${ }^{13} \mathrm{C}-\mathrm{NMR}$ with a JEOL ECP-500 FT-NMR spectrometer, operated at 293.1 K. Chemical shifts are expressed in $\mathrm{ppm}$ from down-field from internal 3-(trimethylsilyl)-1-propane sulfonic acid sodium salt (TPS), but actually measured by reference to internal acetone $\left(\delta=2.225\right.$ for ${ }^{1} \mathrm{H}$ shift and 32.910 for ${ }^{13} \mathrm{C}$ ).

${ }^{1} \mathrm{H}$ and ${ }^{13} \mathrm{C}$ chemical shifts were obtained from a heteronuclear single quantum coherence (HSQC) spectrum, and recorded over spectral widths of $16384 \mathrm{~Hz}\left({ }^{1} \mathrm{H}\right)$ and $32768 \mathrm{~Hz}\left({ }^{13} \mathrm{C}\right)$, with $512 t_{1}$ increments of 1024 data points and 16 scans per increment.

\section{Results}

The milks of the six primates contained $6-8 \%$ total sugar by the phenol-sulfuric acid method: rhesus
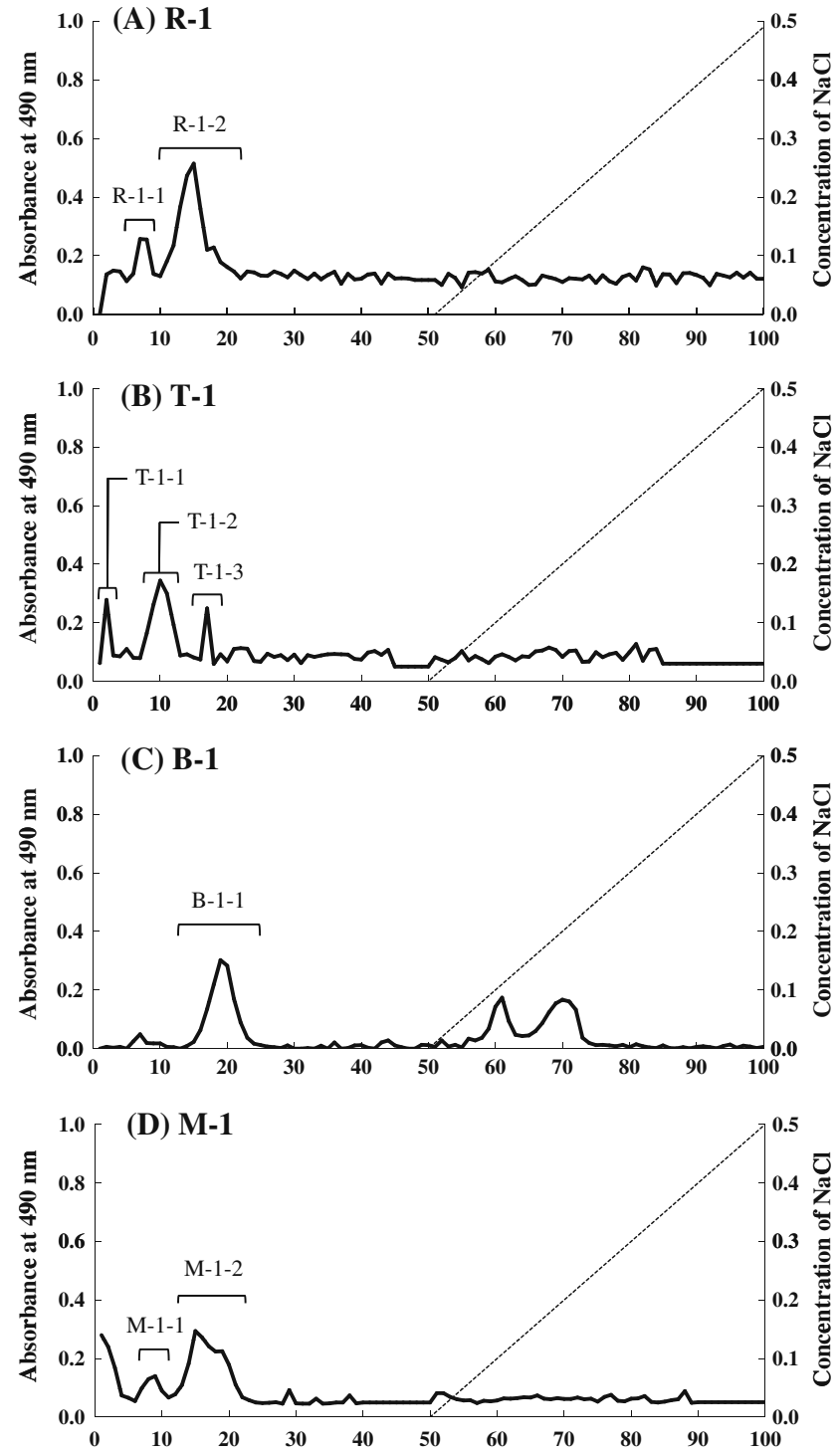

Fig. 3 Anion exchange chromatograms of a R-1, b T-1, c B-1 and d M-1 separated from rhesus macaque, toque macaque, Hamadryas baboon and mantled howler milk, respectively, by gel chromatography on BioGel P-2. A DEAE-Sephadex A-50 column $(1.5 \times 20 \mathrm{~cm})$ equilibrated with $50 \mathrm{mM}$ tris- $\mathrm{HCl}$ buffer solution ( $\mathrm{pH} 8.7$ ) was used. Elution was done first with $250 \mathrm{~mL}$ of the same solution, and then with a linear gradient of the same containing $\mathrm{NaCl}$ from 0 to $0.5 \mathrm{M}$. The flow rate was $15 \mathrm{~mL} / \mathrm{h}$ and $5 \mathrm{~mL}$ fractions were collected. Each fraction was monitored by the phenol- $\mathrm{H}_{2} \mathrm{SO}_{4}$ method

macaque, $7.22 \% \pm 0.44$ s.d. $(n=9)$; toque macaque, $8.09 \% \pm 0.83(n=2)$; Hamadryas baboon, $7.33 \% \pm 0.58$ $(n=3)$; tufted capuchin, $7.54 \% \pm 1.18 \quad(n=3)$; Bolivian squirrel monkey, $6.92 \% \pm 0.44(n=3)$; Mantled howler, $6.05 \% \pm 0.61(n=3)$.

When subjected to size - exclusion chromatography on BioGel P-2, the carbohydrate fraction of each milk sample resolved into several peaks, each of which was designated as in Figs. 1 and 2. Fractions R-1, T-1, B-1, C-1, S-1 and M-1 reacted positively to periodate-resorcinol, showing 


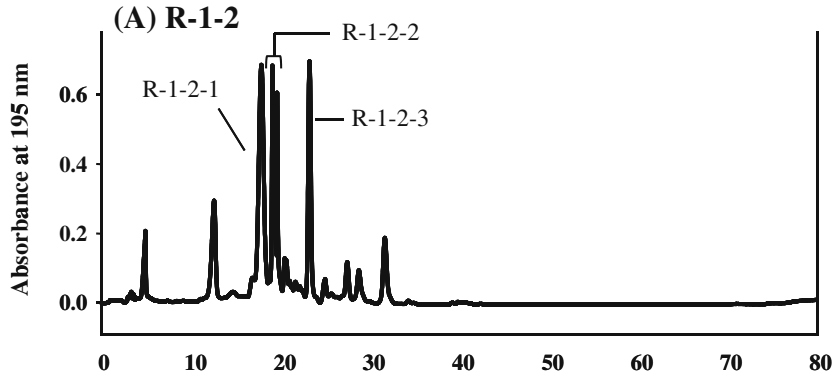

(B) T-1-2

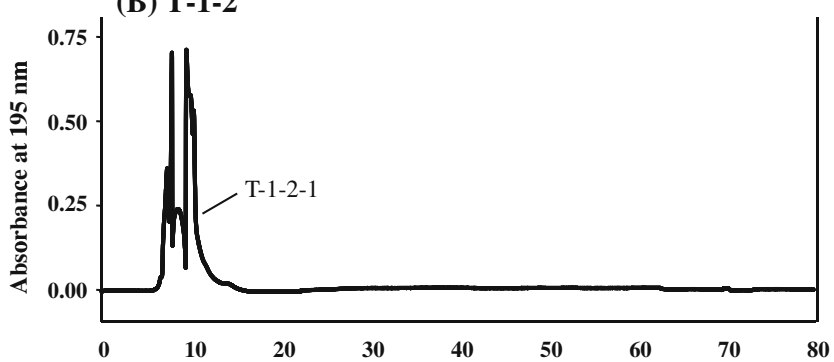

(C) B-1-1

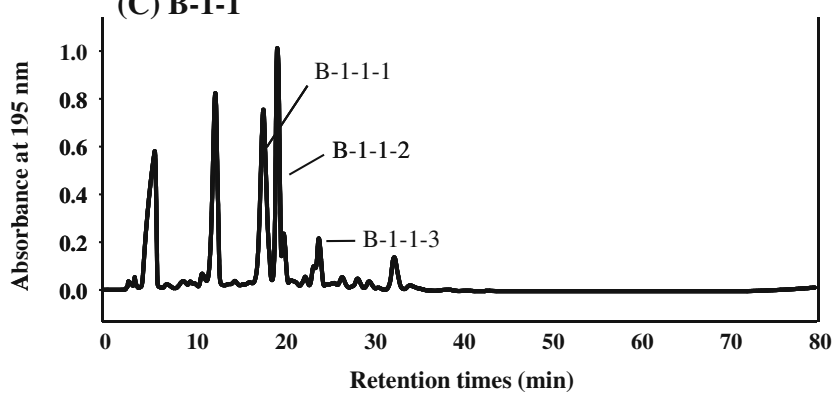

Fig. 4 HPLC of a R-1-2, b T-1-2 and c B-1-1 separated from rhesus macaque, toque macaque and Hamadryas baboon milk, respectively. HPLC was done using a Shimadzu LC-10 AT VP pump on a TSK-gel Amido- 80 column $(4.6 \times 250 \mathrm{~mm}$, pore size $80 \AA$, particle size $5 \mu \mathrm{m})$. The mobile phase was $80 \%$ and $50 \%$ acetonitrile in $15 \mathrm{mM}$ potassium phosphate buffer solution, denoted buffer A and buffer B. Elution was done using a linear gradient of $0 \%$ to $50 \%$ of B buffer for $15 \mathrm{~min}$, followed by $50 \%$ to $100 \%$ of B buffer for $65 \mathrm{~min}$ at $60^{\circ} \mathrm{C}$ at a flow rate of $1 \mathrm{~mL} / \mathrm{min}$. Detection of peaks was done by UV absorption at $195 \mathrm{~nm}$

that they contained sialic acid. Fractions R-1, T-1, B-1 and M-1 were accordingly subjected to anion-exchange chromatography on DEAE-Sephadex A-50; fractions C1 and S-1 were too small for this procedure. During chromatography, the fractions R-1, T-1, B-1 and M-1 each separated into several peaks (Fig. 3), of which the presumptive monosialyl oligosaccharides in fractions R-12, T-1-2, B-1-1 and M-1-2 were used for purification of each sialyl oligosaccharide. The oligosaccharides in each of R-1-2, T-1-2, B-1-1 and M-1-2 as well as in C-1 and S1 (Fig. 2) were further purified by HPLC as shown in Figs. 4 and 5. The components in the predominant peaks of Figs. 1, 2, 4 and 5 were characterized by ${ }^{1} \mathrm{H}-\mathrm{NMR}$ or HSQC.

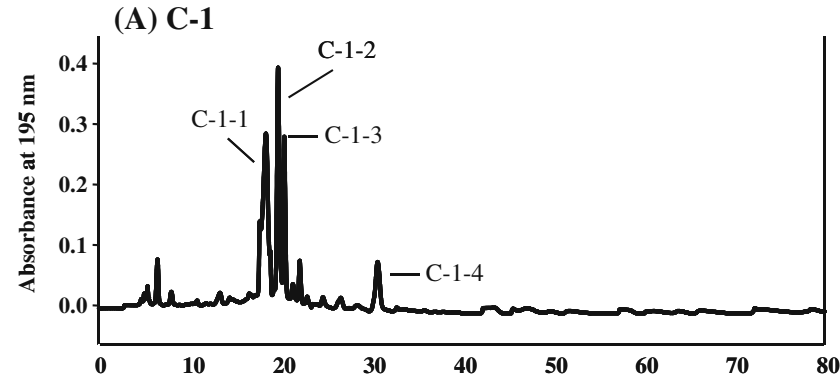

(B) S-1

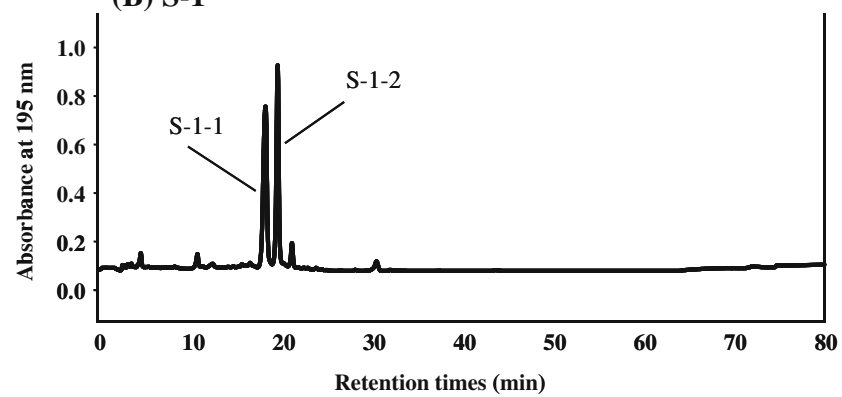

(C) $\mathrm{M}-1-2$

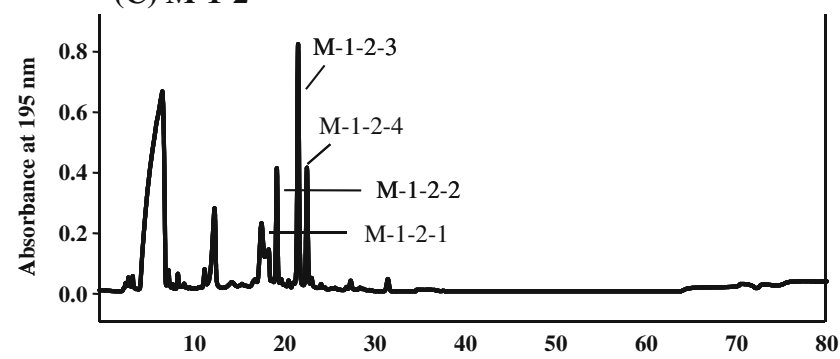

Fig. 5 HPLC of a C-1, b M-1-2 and c S-1 separated from tufted capuchin, mantled howler and Bolivian squirrel monkey milk, respectively. The chromatographies were performed as described in Fig. 4

Rhesus macaque milk oligosaccharides

\section{$R-1-2-1$ and $R-1-2-3$}

As the ${ }^{1} \mathrm{H}-\mathrm{NMR}$ spectra (chemical shifts in Table S1) of the saccharides in R-1-2-1 and R-1-2-3 were essentially identical with those of 3'-NAc-SL and LST c, respectively, these were characterized to be Neu5Ac $(\alpha 2-3) \mathrm{Gal}(\beta 1-4) \mathrm{Glc}$, and Neu5Ac $(\alpha 2-6) \operatorname{Gal}(\beta 1-4) \operatorname{GlcNAc}(\beta 1-3) \operatorname{Gal}(\beta 1-4) \mathrm{Glc}$, respectively.

\section{$R-1-2-2$}

The ${ }^{1} \mathrm{H}-\mathrm{NMR}$ spectrum (Table $\mathrm{S} 1$ ) showed that R-1-2-2 contained two oligosaccharides, one major (R-1-2-2-1) and another minor (R-1-2-2-2). As the anomeric shifts and characteristic resonances of the major component were essentially similar to those of authentic 6 -NAc-SL, the major oligosaccharide (R-1-2-2-1) was considered to be identical with Neu5Ac( $\alpha 2-6) \operatorname{Gal}(\beta 1-4)$ Glc. 
The spectrum of the minor component had the anomeric shifts at $\delta 4.734$ and 4.533 of $\beta(1-4)$ linked GalNAc and $\beta(1-$ 4) linked Gal, respectively; the characteristic $\mathrm{H}-3$ and $\mathrm{H}-4$ shifts of $\beta(1-4)$ linked $G a l$ at $\delta 4.152$ and 4.120 , respectively; H-3 axial and equatorial shifts of $\alpha(2-3)$ linked Neu5Ac at $\delta$ 1.926 and 2.657, respectively; and NAc shifts of $\beta(1-4)$ linked GalNAc and $\alpha(2-3)$ linked Neu5Ac at $\delta 2.014$ and 2.030, respectively. As this pattern was similar to the published data [18] for GM2 tetrasaccharide isolated from bottlenose dolphin milk, the minor saccharide (R-1-2-2-2) was identified as $\operatorname{GalNAc}(\beta 1-4)[\mathrm{Neu} 5 \mathrm{Ac}(\alpha 2-3)] \mathrm{Gal}(\beta 1-4)$ Glc.

It was confirmed that the components in the peaks eluted prior to R-1-2-1 in the HPLC were not saccharides, as shown by their ${ }^{1} \mathrm{H}-\mathrm{NMR}$ spectra. Other minor peak components in Fig. 4a were not characterized in this study, because the amounts were too small.

\section{$R-7, R-6, R-3$ and $R-2$}

As the ${ }^{1} \mathrm{H}-\mathrm{NMR}$ spectra (chemical shifts in Table S2) of the saccharides in R-7, R-6, R-3 and R-2 were essentially identical with those of lactose, 3-FL, LNnT and LNFP III, these were characterized to be $\operatorname{Gal}(\beta 1-4) \mathrm{Glc}, \mathrm{Gal}(\beta 1-4)$ [Fuc $(\alpha 1-3)] \mathrm{Glc}, \operatorname{Gal}(\beta 1-4) \mathrm{GlcNAc}(\beta 1-3) \mathrm{Gal}(\beta 1-4) \mathrm{Glc}$, and Gal $(\beta 1-4)[\mathrm{Fuc}(\alpha 1-3)] \mathrm{GlcNAc}(\beta 1-3) \mathrm{Gal}(\beta 1-4)$ Glc, respectively.

\section{$R-4$}

The ${ }^{1} \mathrm{H}$ spectrum (chemical shifts in Table S2) had the anomeric shifts of $\alpha$-Glc and $\beta$-Glc at $\delta 5.220$ and 4.663, respectively, and $\beta(1-4)$ linked $\mathrm{Gal}$ at $\delta 4.439$. In addition, the spectrum had the anomeric shift of $\beta-N$ acetylhexosamine at $\delta 4.618$ and 4.614, and its NAc shift at $\delta 2.035$, and the characteristic doublet shift of H-4 of $\beta(1-4)$ linked Gal residue at $\delta$ 4.159. This pattern is different from those of $\operatorname{GlcNAc}(\beta 1-3) \operatorname{Gal}(\beta 1-4)$ Glc [23] and $\operatorname{GlcNAc}(\beta 1-6) \operatorname{Gal}(\beta 1-4)$ Glc [17], showing that the saccharide in R-4 differs from these two.

This saccharide was further characterized by ${ }^{13} \mathrm{C}$-NMR (chemical shifts in Table S3) and ${ }^{1} \mathrm{H}_{-}{ }^{13} \mathrm{C}$ HSQC spectrum analysis. The ${ }^{1} \mathrm{H}$ shift of $\mathrm{H}-4$ of the $\beta(1-4)$ linked $\mathrm{Gal}$ at $\delta$ 4.159 correlated with the ${ }^{13} \mathrm{C}$ shift at $\delta 71.2$; this showed that the $\mathrm{OH}-4$ of this residue was not substituted. If this position were substituted, the H-4 shift of $\beta(1-4)$ linked Gal would have correlated with the ${ }^{13} \mathrm{C}$ shift at $\sim 80 \mathrm{ppm}$. The ${ }^{13} \mathrm{C}$ NMR spectrum had the shift at $\delta 84.9$; this shift value was similar to that $(\delta 84.5)$ of $\mathrm{C}-3$ of $\beta(1-4)$ linked Gal residue of $\operatorname{Gal}(\beta 1-3) \operatorname{Gal}(\beta 1-4) G l c$ [24]. Therefore, it was thought that the $\mathrm{OH}-3$ of the $\beta(1-4)$ linked Gal residue of the saccharide was substituted by a $\beta$-hexosamine residue. The residual ${ }^{13} \mathrm{C}$ shifts at $\delta 177.8,106.0,77.7,73.4,70.4$, 55.2 and 24.9 were assigned by comparison with the ${ }^{13} \mathrm{C}$ shifts of free $\beta$-GalNAc and the corresponding shifts of $\beta$ GalNAc of GalNAc( $\beta 1-4)[\operatorname{Neu} 5 A c(\alpha 2-3)] \operatorname{Gal}(\beta 1-4)$ Glc [18]. As these chemical shifts were relatively close to the corresponding shifts of $\beta$-GalNAc of these saccharides, it was concluded that the saccharide in R-4 contained a $\beta$ GalNAc residue; the saccharide in R-4 was therefore characterized to be $\operatorname{GalNAc}(\beta 1-3) \operatorname{Gal}(\beta 1-4) \mathrm{Glc}$.

\section{$R-5$}

The identity of this small peak (Fig. 1a) was not determined.

Toque macaque oligosaccharides

\section{T-9, T-8, T-4 and T-1-2-1}

As the ${ }^{1} \mathrm{H}$-NMR spectra (chemical shifts in Table S4) of the saccharides in T-9, T-8, T-4 and T-1-2-1 were essentially identical with those of lactose, 3-FL, LNFPIII and 3'-NAc-SL, respectively, these were characterized to be $\mathrm{Gal}(\beta 1-4) \mathrm{Glc}, \mathrm{Gal}$ $(\beta 1-4)[\operatorname{Fuc}(\alpha 1-3)] \mathrm{Glc}, \operatorname{Gal}(\beta 1-4)[\operatorname{Fuc}(\alpha 1-3)] \operatorname{GlcNAc}(\beta 1-3)$ $\operatorname{Gal}(\beta 1-4)$ Glc and Neu5Ac( $\alpha 2-3) \operatorname{Gal}(\beta 1-4)$ Glc, respectively. The ${ }^{1} \mathrm{H}-\mathrm{NMR}$ data of T-1-2-1 pointed to another minor sialyl oligosaccharide, which contained $\alpha(2-6)$ linked Neu5Ac, because the ${ }^{1} \mathrm{H}-\mathrm{NMR}$ spectrum had the resonances of H-3 axial and equatorial at $\delta 1.724$ and 2.710 , respectively.

It was confirmed that the components in the peaks eluted prior to T-1-2-1 in the HPLC (Fig. 4b) were not saccharides, as shown by their ${ }^{1} \mathrm{H}-\mathrm{NMR}$ spectra.

\section{$T-2, T-3, T-5, T-6$ and $T-7$}

The identities of these small peaks (Fig. 1b) were not determined.

Hamadryas baboon oligosaccharides

$B-10, B-1-1-1, B-1-1-2$ and $B-1-1-3$

As the ${ }^{1} \mathrm{H}-\mathrm{NMR}$ spectra (chemical shifts in Table S5 and Table S6) of the saccharides in B-10, B-1-1-1, B-1-1-2 and B-1-1-3 were essentially identical with those of lactose, 3'NAc-SL, 6'-NAc-SL and LST c, respectively, these were characterized to be $\operatorname{Gal}(\beta 1-4) \mathrm{Glc}$, Neu5Ac( $\alpha 2-3) \mathrm{Gal}(\beta 1-4)$ Glc, Neu5Ac $(\alpha 2-6) \operatorname{Gal}(\beta 1-4)$ Glc and $\operatorname{Neu} 5 \operatorname{Ac}(\alpha 2-6) \mathrm{Gal}$ ( $\beta 1-4)$ GlcNAc $(\beta 1-3)$ Gal $(\beta 1-4)$ Glc, respectively.

\section{B-9}

The ${ }^{1}$ H-NMR spectrum (chemical shifts in Table S6) showed that B-9 contained two oligosaccharides, B-9-1 
and B-9-2. As their spectra of two oligosaccharides were essentially identical with those of 3-FL and 3'-GL, B-9-1 and B-9-2 were characterized to be $\operatorname{Gal}(\beta 1-4)[\operatorname{Fuc}(\alpha 1-3)]$ Glc and $\operatorname{Gal}(\beta 1-3) \operatorname{Gal}(\beta 1-4)$ Glc, respectively

It was confirmed that the components in the peaks eluted prior to B-1-1 in the HPLC were not saccharides, as shown by their ${ }^{1} \mathrm{H}-\mathrm{NMR}$ spectra. Other minor peak components in Fig. $4 \mathrm{c}$ were not characterized in this study because the amounts were too small.

\section{$B-3$}

The ${ }^{1} \mathrm{H}-\mathrm{NMR}$ spectrum (chemical shifts in Table S6) showed that B-3 contained two oligosaccharides, B-3-1 and B-3-2. The spectrum had the anomeric shifts of $\alpha-\mathrm{Glc}$, two of $\alpha(1-3)$ linked Fuc, of $\beta(1-3)$ linked GlcNAc, of $\beta$ Glc, and of $\beta(1-6)$ linked GlcNAc, and three of $\beta(1-4)$ linked $\mathrm{Gal}$ at $\delta 5.218,5.126$ and 5.105, 4.708, 4.665, 4.637, and $4.466,4.452$ and 4.424 , respectively. It had the characteristic shifts of $\mathrm{H}-4$ of $\beta(1-4)$ linked Gal, which was substituted at $\mathrm{OH}-3$ by a $\beta$-linked GlcNAc, at $\delta 4.142$, of NAc of $\beta(1-6)$ and $\beta(1-3)$ linked GlcNAc at $\delta 2.049$ and 2.020, respectively, and of H-6 of $\alpha(1-3)$ linked Fuc at $\delta$ 1.174. The shifts at $\delta 5.126$ and 5.105 of $\mathrm{H}-1$ of $\alpha(1-3)$ linked Fuc showed the presence of two Lewis $x(\operatorname{Gal}(\beta 1-4)$ $[\operatorname{Fuc}(\alpha 1-3)]$ GlcNAc) units. As this pattern was essentially similar to the published data [25] for DFLNnH and also to fraction O-2 separated from orangutan colostrum [10], one of the oligosaccharides in B-3-1 was characterized to be the $\operatorname{Gal}(\beta 1-4)[\operatorname{Fuc}(\alpha 1-3)] \operatorname{GlcNAc}(\beta 1-3)\{\operatorname{Gal}(\beta 1-4)$ $[\operatorname{Fuc}(\alpha 1-3)] \operatorname{GlcNAc}(\beta 1-6)\} \operatorname{Gal}(\beta 1-4)$ Glc.

The spectrum had other anomeric shifts at $\delta 5.224$ and 4.569 , a characteristic doublet doublet shift at $\delta 4.343$, and a doublet shift at $\delta$ 4.295. As these shifts were essentially similar to anomeric shifts of $\alpha$-Glc and $\beta(1-4)$ linked Gal, and H-3 and H-4 of $\beta(1-4)$ linked Gal of 3'$O$-lactose sulfate, respectively [19], the other oligosaccharide in B-3 (B-3-2) was characterized to be Gal( $\beta 1-4)$ Glc$3^{\prime}-O$-sulfate.

\section{$B-2, B-4, B-5, B-6, B-7$ and $B-8$}

The identities of these small peaks (Fig. 1c) were not determined.

Tufted capuchin oligosaccharides

$$
C-6, C-4, C-2, C-1-1 \text { and } C-1-2
$$

As the ${ }^{1} \mathrm{H}-\mathrm{NMR}$ spectra (chemical shifts in Tables $\mathrm{S} 7$ and S8) of the saccharides in C-6, C-4, C-2, C-1-1 and C-1-2 were essentially identical with those of lactose, LNnT,
LNnH, 3'-NAc-SL and 6'-NAc-SL, respectively, these were characterized to be $\operatorname{Gal}(\beta 1-4) \mathrm{Glc}, \operatorname{Gal}(\beta 1-4) \operatorname{GlcNAc}(\beta 1-3)$ Gal ( $\beta 1-4)$ Glc, Gal $(\beta 1-4) \operatorname{GlcNAc}(\beta 1-3)[\operatorname{Gal}(\beta 1-4)$ GlcNAc $(\beta 1-6)] \operatorname{Gal}(\beta 1-4)$ Glc, Neu5Ac $(\alpha 2-3) \operatorname{Gal}(\beta 1-4)$ Glc and $\operatorname{Neu} 5 \operatorname{Ac}(\alpha 2-6) \operatorname{Gal}(\beta 1-4) \mathrm{Glc}$, respectively.

\section{$C-1-3$}

It was shown that the component in C-1-3 was not a sialyl oligosaccharide by its ${ }^{1} \mathrm{H}-\mathrm{NMR}$ data and it could not be characterized in this study, because the spectrum was unusual.

\section{$C-1-4$}

The spectrum (chemical shifts in Table S7) of the saccharide in C-1-4 had the anomeric shifts of $\alpha$-Glc, $\beta(1-3)$ linked GlcNAc, $\beta$-Glc, $\beta(1-6)$ linked GlcNAc and three $\beta(1-4)$ linked $G a l$ at $\delta 5.220,4.726,4.669,4.647$ and 4.640 , and $4.472,4.455$ and 4.433 , respectively. The spectrum had the characteristic H-3 axial, equatorial, at $\delta$ 1.724 and 2.668, respectively, and NAc of $\alpha(2-6)$ linked Neu5Ac and $\beta(1-6)$ linked GlcNAc at $\delta 2.052$ and 2.061, respectively, and $\mathrm{H}-4$ of $\beta(1-4)$ linked Gal, which was substituted at $\mathrm{OH}-3$ by $\beta$-GlcNAc, at $\delta 4.149$. As this pattern was essentially similar to the published data [26] for MSLNnH and also to that of S-1-4 separated from siamang milk [10], the oligosaccharide in $\mathrm{C}-1-4$ was characterized to be Neu5Ac( $\alpha 2-6) \operatorname{Gal}(\beta 1-4) \operatorname{GlcNAc}(\beta 1$ 3) $[\mathrm{Gal}(\beta 1-4) \operatorname{GlcNAc}(\beta 1-6)] \mathrm{Gal}(\beta 1-4) \mathrm{Glc}$.

It was confirmed that the components in the peaks eluted prior to C-1-1 in the HPLC were not saccharides, as shown by their ${ }^{1} \mathrm{H}-\mathrm{NMR}$. Other minor peak components in Fig. 5a were not characterized in this study because the amounts were too small.

\section{C-3}

The ${ }^{1} \mathrm{H}-\mathrm{NMR}$ spectrum (chemical shifts in Table S8) of the saccharide in C-3 had the anomeric shifts of $\alpha$-Glc, $\beta$-Glc, $\beta(1-6)$ linked GlcNAc, $\beta(1-3)$ linked Gal and two of $\beta(1-4)$ linked $G a l$ at $\delta 5.224,4.669,4.644,4.610$, and 4.500 and 4.472 , respectively, and NAc of $\beta(1-6)$ linked GlcNAc at $\delta$ 2.062. As this pattern was essentially similar to the published data [16] for novo-LNPI separated from tufted (or brown) capuchin colostrum, the oligosaccharide in $\mathrm{C}-3$ was characterized to be $\operatorname{Gal}(\beta 1-3)[\operatorname{Gal}(\beta 1-4) \operatorname{GlcNAc}(\beta 1-6)] \mathrm{Gal}(\beta 1-4) \mathrm{Glc}$.

\section{$C-5$}

The identity of this small peak (Fig. 2a) was not determined. 
Squirrel monkey oligosaccharides

\section{$S-5, S-1-1$ and $S-1-2$}

As the 1H-NMR spectra (chemical shifts in Table S9) of the saccharides in S-5, S-1-1 and S-1-2 were essentially identical with those of lactose, 3'-NAc-SL and 6'-NAc-SL, respectively, these were characterized to be $\operatorname{Gal}(\beta 1-4) \mathrm{Glc}$, Neu5Ac( $\alpha 2-3)$ $\operatorname{Gal}(\beta 1-4)$ Glc and Neu5Ac $(\alpha 2-6) \operatorname{Gal}(\beta 1-4)$ Glc, respectively.

\section{$S-2, S-3$ and $S-4$}

The identities of these small peaks (Fig. 2b) were not determined.

Mantled howler oligosaccharides

$M-8, M-1-2-1$ and $M-1-2-2$

As the ${ }^{1} \mathrm{H}$-NMR spectra (chemical shifts in Table S10) of the saccharides in M-8, M-1-2-1 and M-1-2-2 were essentially identical with those of lactose, $3^{\prime}$-NAc-SL and $6^{\prime}$-NAc-SL, respectively, these were characterized to be Gal $(\beta 1-4)$ Glc, Neu5Ac $(\alpha 2-3) \operatorname{Gal}(\beta 1-4)$ Glc and Neu5Ac $(\alpha 2-6)$ $\operatorname{Gal}(\beta 1-4)$ Glc, respectively.

\section{$M-1-2-3$}

M-1-2-3 was found to have a unique structure, studies on which are the subject of a separate paper.

\section{$M-1-2-4$}

The saccharide in M-1-2-4 could not be characterized by its ${ }^{1} \mathrm{H}-\mathrm{NMR}$ in this study, because the spectrum was unusual.

It was confirmed that the components in the peaks eluted prior to M-1-2-1 in the HPLC were not saccharides, as shown by their ${ }^{1} \mathrm{H}-\mathrm{NMR}$ spectra. Other minor peak components in Fig. 5c were not characterized in this study because the amounts were too small.

\section{$M-2, M-3, M-4, M-5, M-6$ and $M-7$}

The identities of these small peaks (Fig. 2c) were not determined.

\section{Discussion}

All species were found to contain 6-8\% total sugar in their milks, and values are typical for primate milks in general and comparable to those in previous papers [13, 14, 27-29].
In addition, these values are rather similar to those of hylobatid and great apes (5 9\%) [10] and humans (6 7\%).

The ratios of milk oligosaccharides to lactose in the monkey milks could be estimated from the peak areas of the gel chromatograms shown in Figs. 1 and 2. The results were as follows: rhesus macaque milk 1:6; toque macaque milk 1:4; Hamadrys baboon milk 1:4; tufted capuchin milk 1:13; mantled howler milk 1:12; Bolivian squirrel monkey milk 1:23. The ratios observed in the Old World monkey milks were rather similar to those found with chimpanzee (1:4), bonobo (1:5) and siamang (1:3) milks [10], but those of the New World cebid (squirrel monkey, capuchin) and atelid (howler) milks were much lower. In mature human milk the ratio estimated by this method is about 1:2.7 [10]. Thus although oligosaccharide to lactose ratios in Old World monkey and great ape milks approach that of human milk, they are somewhat smaller. We conclude that that the milks of all catarrhine primates that have been studied (including cercepithecoid monkeys, hylobatids, great apes and humans) contain higher concentrations of oligosaccharides than do New World or platyrrhine monkey milks.

This suggests that the oligosaccharide:lactose ratio and total oligosaccharide content have increased following the divergence of catarrhines from platyrhines, which occurred about 32-40 MYA from fossil evidence or even earlier according to some molecular estimates [30-34]. By contrast the divergence between cercopithecoids (such as macaques and baboons) and hominoids (such as great apes) at about 21-29 MYA, and the divergence of Homo from chimps and bonobos at about 4-8 MYA [30, 31, 35, 36] resulted in little if any further increase in total oligosaccharides or oligosaccharide ratios. This assumes that the lower oligosaccharide concentrations and oligosaccharide:lactose ratios in the New World platyrrhine monkeys (atelid and cebids) represent the ancestral condition, rather than a secondary reduction.

In this study zero to three neutral and two to three acidic oligosaccharides were identified in each of the New World platyrrhine monkey milks, and two to five neutral and one to three acidic oligosaccharides in each of the Old World catarrhine monkey milks (Table 2). By comparison, three to six neutral and two to six acidic oligosaccharides were found in each of 4 species of great apes [10]. This suggests a trend for the diversity of oligosaccharides to increase from New World to Old World monkeys, and from cercopithecoid monkeys to great apes. However, in each species one to several minor oligosaccharides that were evident in the chromatograms of milk carbohydrates (Figs. 1-5) could not be characterized due to the small amounts. Further research is needed on larger sample volumes and on additional species to determine if the difference in total milk oligosaccharide content between New World primates and Old World primates is in fact 
Table 2 Comparison of oligosaccharides in the milk of monkeys

\begin{tabular}{|c|c|c|c|c|c|c|c|}
\hline \multicolumn{2}{|c|}{ Type of oligosaccharide } & \multicolumn{6}{|c|}{ Species of primates } \\
\hline & & rhesus macaque & toque macaque & Hamadryas baboon & tufted capuchin & mantled howler & Bolivian squirrel monkey \\
\hline \multirow[t]{8}{*}{ Neutral } & tri & 3-FL & 3-FL & $3-\mathrm{FL}$ & & & \\
\hline & & 6'-GL & & & & & \\
\hline & & 3'-GalNAcL & & & & & \\
\hline & tetra & LNnT & & & $\mathrm{LNnT}$ & & \\
\hline & penta & LNFP III & LNFP III & & & & \\
\hline & & & & & novo LNP I & & \\
\hline & hexa & & & & $\mathrm{LNnH}$ & & \\
\hline & octa & & & DFLNnH & & & \\
\hline \multirow[t]{6}{*}{ Acidic } & di & & & L-3'-S & & & \\
\hline & tri & 3'-NAc-SL & 3'-NAc-SL & 3'-NAc-SL & 3'-NAc-SL & 3'-NAc-SL & 3'-NAc-SL \\
\hline & & $6^{\prime}-\mathrm{NAc}-\mathrm{SL}$ & & $6^{\prime}-\mathrm{NAc}-\mathrm{SL}$ & $6^{\prime}$-NAc-SL & $6^{\prime}-\mathrm{NAc}-\mathrm{SL}$ & $6^{\prime}-\mathrm{NAc}-\mathrm{SL}$ \\
\hline & tetra & $\mathrm{GM}_{2}$ tetra & & & & & \\
\hline & penta & LSTc & & LSTc & & & \\
\hline & hepta & & & & MSLNnH & & \\
\hline
\end{tabular}

matched by a comparable increase in the diversity of milk oligosaccharides. Certainly no non-human primate studied to date comes close to the extraordinary diversity in milk oligosaccharides observed in human milk [3-5].

As described in the Introduction, type I oligosaccharides predominate over type II in human milk, but not in the milk of the great apes, in which type II predominate over type I. In this study, type II oligosaccharides were found in the milks of the cercopithecids and in milk of the tufted capuchin, but type I oligosaccharides were not detected. In mantled howler and Bolivian squirrel monkey milks lactose was the only neutral saccharide that was identified, and acidic oligosaccharides had lactose as the core unit, but other oligosaccharides present at very low concentrations (Fig. 2) could not be identified. Our data suggest that type I milk oligosaccharides were acquired by the common ancestor of apes and humans after divergence from cercopithecoid monkeys. At present, the particular biological significance of the predominance of type I oligosaccharides in human milk is uncertain, but we hypothesize that it may be relevant to bifidus flora formation in the neonatal infant colon, because a specific metabolic pathway for type I but not type II oligosaccharides has been found in certain bifidobacterial strains such as Bifidobacterium bifidum [5, 37, 38].

It is noteworthy that oligosaccharides containing Lewis $\mathrm{x}$ as well as 3-FL were found in the milks of the three species of cercopithecid monkeys. In our previous study [10], these oligosaccharides were found in milk or colostrum of chimpanzee, bonobo and orangutan, but not in those of gorilla and siamang. This type of milk oligosaccharide appears to have existed in the common catarrhine ancestor of Old World monkeys, apes and humans, and has subsequently been lost from the milk/colostrum of a few ape species such as gorilla and siamang. However, we cannot rule out the possibility that other individual gorillas or siamangs may contain these oligosaccharides at low concentrations, and that we happened to study individuals in which these could not be measured; inter-individual variation in milk oligosaccharides has been observed in humans. It is noteworthy that Lewis $\mathrm{x}$ and 3-FL were not identified in the milks of the howler or cebid monkeys, even though 3-FL had been found in tufted capuchin colostrum in a previous study [16]. It is possible that 3-FL was present in capuchin milk and other New World monkey milks but at such a low concentration (e.g., peaks C-5, S-4, M-7 in Fig. 2) that we could not identify it due to the small amounts of milk $(5-7 \mathrm{ml})$ available for study.

Although Fuc $(\alpha 1-2) \operatorname{Gal}(\beta 1-4) \mathrm{Glc}\left(2^{\prime}-\mathrm{FL}\right)$ is the most prominent oligosaccharide in human milk/colostrum [6] and was found in the milk or colostrum of chimpanzee, bonobo and gorilla [10], this trisaccharide was not found in the milks of any of the monkeys in this study, nor was it detected in tufted capuchin colostrum in our previous study [16]. This trisaccharide reduces the incidence of diarrhea caused by Campylobacter jejuni in breast fed human infants [39]; it is possible that milk $2^{\prime}$-FL was acquired by the ape/human lineage following its divergence from other primates.

Oligosaccharides containing $N$-glycolylneuraminic acid (Neu5Gc) were not found in the milks of the monkeys in this study. In our previous study, $\operatorname{Neu} 5 \operatorname{Gc}(\alpha 2-3) \operatorname{Gal}(\beta 1-4)$ Glc was detected in milk or colostrum of chimpanzee, bonobo, gorilla and orangutan, but not in siamang milk [10]. Glycoconjugates containing Neu5Gc are absent from 
the tissues or body fluids, including milk/colostrum, of healthy humans because of the absence of the hydroxylating enzyme that converts CMP-Neu5Ac to CMP-Neu5Gc [40]. It is worth noting that among primate species studied to date, only great ape milk or colostrum has been found to contain this type of oligosaccharide. It is possible, however, that Neu5Gc-containing glycoconjugates could be present in other tissues or body fluids of primates.

It is interesting that among the monkeys studied, only rhesus macaque milk had oligosaccharides containing GalNAc such as GalNAc( $(\beta 1-3) \operatorname{Gal}(\beta 1-4)$ Glc and GM2 tetrasaccharide. This type of saccharide has previously been found only in rhesus macaque milk and not in any other primates, including apes and humans. Further studies will clarify whether GalNAc-containing saccharides are found in the milk/colostrum of other primate species. GM2 tetrasaccharide has previously been found only in bottlenose dolphin milk [18].

It was surprising that $3^{\prime}$-O-lactose sulfate was found in baboon milk, but only baboon milk. This disaccharide or oligosaccharides containing sulfate have been found in the milks of the dog [19], bearded seal [41, 42] and humans [43]. Further study is needed to clarify if sulfated saccharides occur in the milk or colostrum of other primates.

Lacto-N-novopentaose I was found only in tufted capuchin milk and had previously been detected in tufted capuchin colostrum [10]. To date the tufted capuchin is the only primate in which milk/colostrum contains this pentasaccharide. Among non-primates it has been found in milk or colostrum of the tammar wallaby [44], cow [45] and horse [46], too.

This study found common features among the milk oligosaccharides of monkeys of three families (Atelidae, Cebidae, Cercopithecidae) as well as apparent differences among these taxa and apes and humans. It also found that there are specific milk oligosaccharides in certain monkey species that appear to be absent from the milks of other primates that have been studied. From our previous and present studies, we conclude that human oligosaccharides are unique insofar as they consist of many varieties of oligosaccharides of both types I and II, with type I predominating, and that the ratio of oligosaccharides to lactose is somewhat higher than that found in other primates. The question of how these human-specific features may relate to elements of human evolution such as expansion of brain size, change in locomotor pattern to bipedalism, production of relatively immature neonates and transition to larger social groups is open to speculation.

Although the results of HPLC-Chip/TOF-MS analysis [47] have suggested the presence of almost 200 oligosaccharides in human milk/colostrum, it has been found that the predominant oligosaccharides are $2^{\prime}$-FL, LNFPI,
LNDFHI and LNT [3]. It is thought that $2^{\prime}$-FL can act as a receptor analogue that inhibits the attachment of Campylobacter jejuni to the infant colonic mucosa [48], while LNT, LNFPI and LNDFHI can be utilized as prebiotics that stimulate the growth of Bifidobacteria, including Bifidobacterium bifidum, within the infant colon $[37,38,49,50]$. Our results indicate that these oligosaccharides are all either absent or present in only trace amounts in the milk of these New and Old World monkeys; this difference between humans and monkeys may have biological significance. In human milk/colostrum, the dominant acidic oligosaccharides are LST c, 6'-SL, DSLNT (Neu5Ac $(\alpha 2-3) \operatorname{Gal}(\beta 1-4)$ $[\mathrm{Neu} 5 \mathrm{Ac}(\alpha 2-6)] \mathrm{GlcNAc}(\beta 1-3) \mathrm{Gal}(\beta 1-4) \mathrm{Glc})$ and $3^{\prime}-\mathrm{SL}$ in this order, but in the milk of the monkeys $3^{\prime}$-SL predominates over 6 '-SL. The biological significance of each of the major milk oligosaccharides should be easier to assess following accurate quantitation.

Since this study is based on a limited number of individuals per species, and only a handful of species, further studies using larger milk samples and additional individuals and species are required to confirm suggested phylogenetic patterns.

Acknowledgements We thank Michael Jakubasz and Regina Eisert for assistance in selecting and preparing samples at the Nutrition Laboratory of the Smithsonian National Zoological Park. Collection of rhesus macaque milk was supported in part by National Institutes of Health grants RR019970 to John Capitanio and RR000169 to the California National Primate Research Center. Toque macaque field research was supported by grants to W. Dittus from the US National Science Foundation (BNS-9510894) and the Earthwatch Institute, Boston, MA, and Sunil Gunathilake assisted with the collection of milk samples. Collection of capuchin milk was supported by a grant to LA Milligan from the LSB Leakey Foundation 1965. Squirrel monkey research was made possible by Grant Number P40 RR01254 from the National Center for Research Resources (NCRR), a component of the National Institutes of Health (NIH). Mantled howler research was supported by a grant to K. Glander from the Earthwatch Institute, Boston, MA and Kay Izard assisted with collection of milks. The contents of this paper are solely the responsibility of the authors and do not necessarily reflect the official views of the funding agencies. Samples obtained from primate research institutes were collected under Animal Care and Use authorizations of these organizations and/ or the universities of the coauthors.

Open Access This article is distributed under the terms of the Creative Commons Attribution Noncommercial License which permits any noncommercial use, distribution, and reproduction in any medium, provided the original author(s) and source are credited.

\section{References}

1. Newburg, D.S., Neubauer, S.M.: Carbohydrates in milks: Analysis, quantities and significance. In: Jensen, R.G. (ed.) Handbook of Milk Composition, pp. 273-249. Academic, San Diego (1995)

2. Kunz, C., Rudloff, S., Baier, W., Klein, N., Strobel, S.: Oligosaccharides in human milk: Structural, functional, and metabolic aspects. Annu. Rev. Nutr. 20, 699-722 (2000) 
3. Urashima, T., Asakuma, S., Messer, M.: Milk oligosaccharides. In: Kamerling, J.P.Y. (ed.) Comprehensive Glycoscience, pp. 695724. Elsevier, Amsterdam (2007)

4. Amano, J., Osanai, M., Orita, T., Sugawara, D., Osumi, K.: Structural determination by negative - ion MALDI-QIT-TOFMS ${ }^{\mathrm{n}}$ after pyrene derivatization of variously fucosylated oligosaccharides with branched decaose cores from human milk. Glycobiology 19, 601-614 (2009). doi:10.1093/glycob/cwp026

5. Urashima, T., Kitaoka, M., Asakuma, S., Messer, M.: Milk oligosaccharides. In: McSweeney, P.L.H., Fox, P.F. (eds.) Advanced Dairy Chemistry, Vol. 3, Lactose, Water, Salts and Minor Constituents, pp. 295-349. Springer Science+Business Media, New York (2009)

6. Asakuma, S., Nakamura, T., Kimura, K., Watanabe, Y., Akahori, M., Ohbayashi, H., Arai, I., Sanai, Y., Urashima, T.: Determination of major neutral oligosaccharide content of human colostrum. Eur. J. Clin. Nutr. 62, 488-484 (2008)

7. Thurl, S., Muller-Wermer, B., Sawatzki, G.: Quantification of individual oligosaccharide compounds from human milk using high $-\mathrm{pH}$ anion exchange chromatography. Anal. Biochem. 235, 202-206 (1996)

8. Coppa, G.V., Pierani, P., Zampini, L., Carloni, I., Carlucci, A., Catacci, C., Gabrielli, O.: Oligosaccharides in human milk during different phases of lactation. Acta Paediatr. 430, 89-94 (1999)

9. Chaturvedi, P., Warren, C.D., Altaye, M., Morrow, A.L., RuizPalacios, G., Pickerling, L.K., Newburg, D.S.: Fucosylated human milk oligosaccharides vary between individuals and over the course of lactation. Glycobiology 11, 365-370 (2001)

10. Urashima, T., Odaka, G., Asakuma, S., Uemura, Y., Goto, K., Senda, A., Saito, T., Fukuda, K., Messer, M., Oftedal, O.T.: Chemical characterization of oligosaccharides in chimpanzee, bonobo, gorilla, orangutan, and siamang milk or colostrum. Glycobiology 19, 499-508 (2009). doi:10.1093/glycob/cwp006

11. Dittus, W.P.J.: Birth sex ratios in toque macaques and other mammals: integrating the effects of maternal condition and competition. Behav. Ecol. Sociobiol. 44, 149-160 (1998)

12. Hoelzer, G.A., Dittus, W.P.J., Ashley, M.V., Melnick, D.J.: The local distribution of highly divergent mitochondrial DNA haplotypes in toque macaques at Polonnaruwa, Sri Lanka. Mol. Ecol. 3, 453-458 (1994)

13. Milligan, L.A.: Milk composition of captive tufted capuchins (Cebus apella). Am. J. Primatol. 72, 81-86 (2010)

14. Milligan, L.A., Gibson, S.V., Williams, L.E., Power, M.L.: The composition of milk from Bolivian squirrel monkeys (Saimiri boliviensis boliviensis). Am. J. Primatol. 70, 35-43 (2008)

15. Glander, K.E.: Dispersal patterns in Costa Rican mantled howling monkeys. Int. J. Primatol. 13, 415-436 (1992)

16. Urashima, T., Kawai, Y., Nakamura, T., Arai, I., Saito, T., Namiki, M., Yamaoka, K., Kawahara, M., Messer, M.: Chemical characterization of six oligosaccharides in a sample of colostrum of the brown capuchin, Cebus apella (Cebidae: Primates). Comp. Biochem. Physiol. C124, 295-300 (1999)

17. Urashima, T., Bubb, W.A., Messer, M., Tsuji, Y., Taneda, Y.: Studies of the neutral trisaccharide of goat (Capra hircus) colostrum and of the one- and two-dimensional ${ }^{1} \mathrm{H}$ and ${ }^{13} \mathrm{C}$ NMR spectra of $6{ }^{\prime}-\mathrm{N}$ acetylglucosaminyllactose. Carbohydr. Res. 262, 173-184 (1994)

18. Uemura, Y., Asakuma, S., Nakamura, T., Arai, I., Taki, M., Urashima, T.: Occurrence of a unique sialyl tetrasaccharide in colostrum of a bottlenose dolphin (Tursiops truncatus). Biochim. Biophys. Acta 1775, 290-297 (2005)

19. Bubb, W.A., Urashima, T., Kohso, K., Nakamura, T., Arai, I., Saito, T.: Occurrence of an unusual lactose sulfate in dog milk. Carbohydr. Res. 318, 123-128 (1999)

20. Dubois, M., Gilles, K.A., Hamilton, J.K., Roberts, P.A., Smith, F.: Colorimetric method for determination of sugars and related substances. Anal. Chem. 28, 350-356 (1956)
21. Maier, J.R., Boulet, M.: Direct analysis of lactose in milk and serum. J. Dairy Sci. 42, 1390-1391 (1959)

22. Jourdian, G.W., Dean, L., Roseman, S.: The sialic acids: XI. A periodate - resorcinol method for the quantitative estimation of free sialic acids and their glycosides. J. Biol. Chem. 356, 430-435 (1971)

23. Tsuji, Y., Urashima, T., Matsuzawa, T.: The characterization of UDP-N-acetylglucosamine: Gal $\beta 1-4 G l c(N A c) \beta 1-3$ N-acetylglucosaminyltransferase in fluids from rat rete testis. Biochim. Biophys. Acta 1289, 115-121 (1996)

24. Urashima, T., Saito, T., Nishimura, J., Ariga, H.: New galactosyllactose containing $\alpha$-glycosidic linkage isolated from ovine (Booroola dorset) colostrum. Biochim. Biophys. Acta 992, 375378 (1989)

25. Haeuw-Fievre, S., Wieruszeski, J.M., Plancke, Y., Michalski, J.C., Montreuil, J., Strecker, G.: Primary structure of human milk octa, dodeca- and tridecasaccharides determined by a combination of ${ }^{1} \mathrm{H}-\mathrm{NMR}$ spectroscopy. Evidence for a new core structure, the para-lacto-N-octaose. Eur. J. Biochem. 215, 361-371 (1993)

26. Gronberg, G., Lipniunas, P., Lundgren, T., Erlansson, K., Lindh, F., Nillson, B.: Isolation of monosialylated oligosaccharides from human milk and structural analysis of three new compounds. Carbohydr. Res. 191, 261-178 (1989)

27. Oftedal, O.T., Iverson, S.J.: Comparative analysis of nonhuman milks: phylogenetic variation in the gross composition of milks. In: Jensen, R.G. (ed.) Handbook of Milk Composition, pp. 749 788. Academic, San Diego (1995)

28. Power, M.L., Oftedal, O.T., Tardif, S.D.: Does the milk of callitrichid monkeys differ from that of larger anthropoids? Am. J. Primatol. 56, 117-127 (2002)

29. Hinde, K., Power, M.L., Oftedal, O.T.: Rhesus macaque milk: Magnitude, sources and consequences of individual variation over lactation. Am. J. Phy. Anthropol. 138, 148-157 (2008)

30. Gingerich, P.D.: Primate evolution: evidence from the fossil record, comparative morphology, and molecular biology. Am. J. Phy. Anthropol. 27, 57-72 (1984)

31. Glazko, G.V., Nei, M.: Estimation of divergence times for major lineages of primate species. Mol. Biol. Evol. 20, 424-434 (2003)

32. Opazo, J.C., Wildman, D.E., Prychitko, T., Johnson, R.M., Goodman, M.: Phylogenetic relationships and divergence times among New World monkeys (Platyrrhini, Primates). Mol. Phylogenet. Evol. 40, 274-280 (2006)

33. Hodgson, J.A., Sterner, K.N., Matthews, L.J., Burrell, A., Jani, R.A., Raaum, R.L., Stewart, C.-B., Distotell, T.R.: Successive radiations, not stasis, in the South American primate fauna. Proc. Natl Acad. Sci. USA 106, 5534-5539 (2009)

34. Rosenberger, A.: Platyrrhines, PAUP, parallelism, and the long lineage hypothesis: A reply to Kay et al. (2008). J. Human Evol., in press (2010). doi:10.1016/j.jhevol.2010.03.003

35. Hobolth, A., Christensen, O.F., Mailund, T., Schierup, M.H.: Genomic relationships and speciation times of human, chimpanzee, and gorilla inferred from a coalescent hidden Markov model. PLoS Genet. 3(2), 294-304 (2007)

36. Caswell, J.L., Mallik, S., Richter, D.J., Neubauer, J., Schirmer, C., Gnerre, S., Reich, D.: Analysis of chimpanzee history based on genome sequence alignments. PLoS Genet. 4(4), 1-14 (2008)

37. Kitaoka, M., Tian, J., Nishimoto, M.: Novel putative galactose operon involving lacto-N-biose phosphorylase in Bifidobacterium longum. Appl. Environ. Microbiol. 71, 3158-3162 (2005)

38. Wada, J., Ando, T., Kiyohara, M., Ashida, H., Kitaoka, M., Yamaguchi, M., Kumagai, H., Katayama, T., Yamaoto, K.: Lacto-N-biosidase from Bifidobacterium bifidum, a critical enzyme for the degradation of human milk oligosaccharides with a type-I structure. Appl. Environ. Microbiol. 74, 39964004 (2008)

39. Morrow, A.L., Ruiz-Palacios, G.M., Altaye, M., Jiang, X., Guerrero, M.L., Meinzen-Derr, J.K., Farkas, T., Chaturvedi, P., 
Pickerring, L.K., Newburg, D.S.: Human milk oligosaccharides are associated with protection against diarrhea in breast-fed infants. J. Pediatr. 145, 297-303 (2004)

40. Brinkman-Van der Linden, E.C.M., Sjoberg, E.R., Raj Juneja, L., Crocker, P.R., Varki, N., Varki, A.: Loss of N-glycolylneuraminic acid in human evolution. Implications for sialic acid recognition by siglecs. J. Biol. Chem. 275, 8633-8640 (2000)

41. Urashima, T., Nakamura, T., Nakagawa, D., Noda, M., Arai, I., Saito, T., Lydersen, C., Kovacs, K.M.: Characterization of oligosaccharides in milk of bearded seal (Erignathus barbatus). Comp. Biochem. Physiol. B138, 1-18 (2004)

42. Kinoshita, M., Ohta, H., Higaki, K., Kojima, Y., Urashima, T., Nakajima, K., Suzuki, M., Kovacs, K.M., Lydersen, C., Hoyakawa, T., Kakehi, K.: Structural characterization of multi-branched oligosaccharides from seal milk by combination of off-line HPLCMALDI-TOF MS and sequential exoglycosidase digestion. Anal. Biochem. 388, 242-253 (2009)

43. Guerardel, Y., Morelle, W., Plancke, Y., Lemoine, J., Stercker, J.: Structural analysis of five new monosialylated oligosaccharides from human milk. Arch. Biochem. Biophys. 296, 597-610 (1999)

44. Bradbury, J.H., Collins, J.G., Jenkins, G.A., Trifonoff, E., Messer, M.: ${ }^{13} \mathrm{C}-\mathrm{NMR}$ study of the structures of two branched oligosaccharides from marsupial milk. Carbohydr. Res. 122, 136-140 (1983)

45. Urashima, T., Saito, T., Ohmisya, K., Shimazaki, K.: Structural determination of three neutral oligosaccharides in bovine (Hol-
stein-Froesian) colostrum, including the novel trisaccharide: GalNAc $\alpha 1-3$ Gal $\beta 1-4$ Glc. Biochim. Biophys. Acta 1200, 64-72 (1991)

46. Urashima, T., Sakamoto, T., Ariga, H., Saito, T.: Structure determination of three neutral oligosaccharides obtained from horse colostrum. Carbohydr. Res. 194, 280-287 (1989)

47. Ninonuevo, M.R., Park, Y., Yin, H., Zhang, J., Ward, R.E., Clowers, B.H., German, J.B., Freeman, S.L., Killeen, K., Grimm, R., Lebrilla, C.B.: A strategy for annotating the human milk glycome. J. Agric. Food Chem. 54, 7471-7480 (2006)

48. Ruiz-Palacios, G.M., Cervantes, L.E., Ramos, P., ChavezMunguia, B., Newburg, D.S.: Campylobacter jejuni binds intestinal $\mathrm{H}(\mathrm{O})$ antigen (Fuc $\alpha 1,2 \mathrm{Gal} \beta 1,4 \mathrm{GlcNAc}$ ), and fucosyloligosaccharides of human milk inhibit its binding and infection. J. Biol. Chem. 554, 135-143 (2004)

49. Katayama, T., Sakuma, A., Kimura, T., Makimura, Y., Hiratake, J., Sakata, K., Yamanoi, T., Kumagai, H., Yamamoto, K.: Molecular cloning and characterization of Bifidobacterium bifidum 1, 2- $\alpha$-L-fucosidase (AfcA), a novel inverting glycosidase (glyco hydrolase family 95). J. Bacteriol. 186, 4885-4893 (2004)

50. Ashida, H., Miyake, A., Kiyohara, M., Wada, J., Yoshida, E., Kumagai, H., Katayama, T., Yamamoto, K.: Two distinct $\alpha$-Lfucosidases from Bifidobacterium bifidum are essential for the utilization of fucosylated milk oligosaccharides and glycoconjugates. Glycobiology 19, 1010-1017 (2009) 